\title{
Vilãs, Mocinhas ou Heroínas: linguagem do corpo feminino nos quadrinhos
}

\author{
Villains, Ladies or Heroines: female body language in comics
}

Villana, Señoras o las heroínas: lenguaje corporal mujeres en comics

\author{
Kelli Carvalho Melo \\ Universidade Federal da Grande Dourados - Brasil \\ kelli_geo@hotmail.com \\ Maria Ivanilse Calderón Ribeiro \\ Universidade Federal de Rondônia - Brasil \\ ivanilsecr@gmail.com
}

\section{Resumo}

O presente trabalho traz uma abordagem de como a figura feminina é representada nas histórias em quadrinhos. $\mathrm{O}$ objetivo do trabalho é identificar o discurso criado em torno da imagem feminina, que intercala da heroína destemida a mocinha em perigo que necessita da proteção masculina. Vamos realizar uma análise a partir das histórias em quadrinhos da Mulher-Maravilha. Fica evidente que são necessários abordagens mais acurada a respeito das HQs, ainda mais quando tratamos de gênero, pode parecer exagerado mas essa visão redutora da mulher que é passada nos quadrinhos é parte de um problema maior, é algo que é reflexo da nossa sociedade, que necessita ser desconstruído.

Palavras-Chave: Representação; HQs; Gênero; Mulher-Maravilha.

\begin{abstract}
This article presents an approach of how the female figure is represented in comics. The objective is to identify the discourse created about the female image in this genre, that merges the fearless heroine with the damsel in distress, who needs male protection. We will perform an analysis of the Wonder Woman comics. It is evident that a more accurate approach about those comics is needed, especially when dealing with gender. However exaggerated it may seem, the reductive view of women that is passed on by the comics is part of a larger problem, it is something that reflects our society, and needs to be deconstructed.
\end{abstract}

Keywords: Representation; Comics; Gender; Wonder Woman. 


\section{Resumen}

En este trabajo se presenta una aproximación a la forma en la figura femenina representada en los cómics. El objetivo es identificar el discurso creado en torno a la imagen femenina que combina la joven heroína valiente en apuros necesita protección masculina. Vamos a realizar un análisis de los cómics de Wonder Woman. Es evidente que una mayor precisión acerca de los enfoques dibujos animados, incluso cuando se trata de sexo, puede parecer exagerado, pero esta visión reductiva de la mujer que se pasa en los cómics es parte de un problema mayor, es algo que es un reflejo de nuestra sociedad que necesita ser deconstruido.

Palabras-Clave: Representación; Comics; Género; Wonder Woman.

\section{Introdução}

As histórias em quadrinhos fazem parte do imaginário popular, as narrativas apresentadas nos quadrinho são denominadas como gênero típico de massa, segundo Minayo (1992). Dessa forma, conseguem atrair públicos bem distintos e de diferentes meios econômicos ou sociais, sendo as crianças, os jovens e os adultos.

São quadros capazes de determinar a imaginação, de narrar histórias determinando local, espaço ou tempo. Mantêm e criam certa informação, capazes de terminar a representação do que se mostra ou é falado. De acordo com Barcellos (1995), tudo que se passa nas histórias em quadrinhos pode ser visto como apropriação do imaginário que são ou podem vir a ser aceitos como reais, ou seja, os quadrinhos são representações do nosso imaginário, que gostaríamos que fossem reais.

As histórias em quadrinhos como meio de entretenimento que consegue alcançar um público distinto, mesmo que a grande maioria seja, ainda, do sexo masculino. Desde que surgiram, elas se adaptaram e integraram ao contexto sócio-histórico ao qual estavam inseridas, isso não é novidade para um meio de informação. Dessa forma, as apreensões e representações que as HQs fazem sempre estão carregadas de valores, ideias, anseios, tanto dos criadores quanto dos leitores, talvez seja por essa razão que a sexualidade feminina é expressa com tanta veemência.

As personagens femininas aparecem sempre de forma redutora, elas possuem três perfis, aparecem como mocinhas indefesas à espera de seu herói, ou são as vilãs sem escrúpulos que tentam a masculinidade dos heróis com o seu traje minúsculo e sua falta de moral, ou ainda a heroína com superpoder ou não, que geralmente é jovem e bela, desenhada em posições sensuais que enfatizam seus atributos físicos.

Vamos analisar a personagem da MulherMaravilha, uma das primeiras heroínas das histórias em quadrinhos a ter uma repercussão grande. A personagem surge em um contexto sócio-histórico conturbado em meio a Segunda Guerra Mundial, no qual o papel das mulheres tomava outros rumos, a mulher deixa de fazer parte somente do universo da casa e passa a assumir papéis, até então, ditos masculinos.

A Mulher-Maravilha é uma personagem de particularidade forte, é uma amazona, uma guerreira que luta por justiça e paz, características de uma deusa, que é orgulhosa e não aceita a ajuda masculina. São essas as características que possuía em sua gênese no auge da Segunda Guerra Mundial, que foram totalmente redefinidas com o término da mesma, ela passa a depender do sexo masculino e suas curvas são mais exploradas, 
isto é, sua feminilidade.

O que buscamos em nosso trabalho é analisar esse discurso tão impregnado que os quadrinhos trazem da figura feminina e seu corpo, que estão intimamente relacionados à imoralidade, as roupas justas e decotadas, a falta de pudor ao desfilar sua feminilidade e/ou sexualidade.

\section{Representações da Figura Feminina nos Quadrinhos}

As histórias em quadrinho apresentam-se como formas organizadas de produção cultural que visam atingir as mais variadas camadas da sociedade, talvez seja pelo fato de serem oriundas de duas artes diferentes escrita e desenho, o que permite auferir o debate e a interpretação sobre elementos necessários à compreensão do mundo atual.

Compreender e chamar a atenção de gerações é determinante para a construção de uma representação, podendo esta ser benéfica ou não. É perecível a caracterização de vários conceitos ou mesmo pré-conceitos de personagens tratados.

São representações do imaginário da sociedade, que busca por meio delas auferir um discurso ou representar algo da realidade. A Representação Social está associada à "reprodução de uma percepção retida na lembrança ou do conteúdo do pensamento" na Filosofia, e nas Ciências Sociais são definidas como "categorias de pensamento que expressam a realidade, explicam-na, justificando-a ou questionando-a" (MINAYO, 1992, p. 158).

No intuito de representar o que se vê na realidade, ou mesmo o que se espera que seja visto ou praticado pelo público alvo, conscientizando de forma direta os leitores. Contudo, existe também o estereótipo dos personagens dos quadrinhos.

As representações estão intimamente ligadas às práticas culturais, de acordo com
Pesavento (2003, p. 39-40) formam uma "realidade paralela à existência dos indivíduos, mas fazem os homens viverem por elas e nelas" [...], tem o poder de substituir o mundo real mesmo sendo "construídas sobre o mundo não só se colocam no lugar deste mundo, como fazem com que os homens percebam a realidade e pautem a sua existência". No entanto, a representação não é copia fiel da realidade, mas uma construção feita a partir do mundo.

Assim, as histórias em quadrinhos se apresentam como uma construção da realidade da existência do ser humano, onde estes procuram substituir o mundo real por um fictício, um que faz parte de sua imaginação. São carregadas de ideologias.

As HQs são um meio de informações e de críticas sociais, que se apresentam explícitas ou implícitas, assim, conseguindo atingir uma grande quantidade de leitores. Têm a possibilidade de realizar a leitura geográfica de mundo, de culturas em seu estabelecimento de diferentes temporalidades e espacialidades (CARVALHO MELO, MEDEIROS, ALMEIDA SILVA, 2013).

Os quadrinhos, desde sua gênese, sendo convencionado como marco inicial o Yellow $\mathrm{Kid}$, produzido pelos norte-americanos por volta do ano de 1895, estiveram presentes em discursos ideológicos. Nas HQs estão representações da realidade, ou daquilo que se deseja transformar em realidade.

A leitura dos quadrinhos deve ser desenvolvida a partir da natureza da sua relação com a realidade social, uma vez que os quadrinhos são uma expressão complexa da produção contemporânea. Além da função de distração e lazer, têm a função mítica e fabuladora, característica da ficção, preenchendo funções estéticas, por se tratar de uma linguagem artística (ARANHA, 1986).

De acordo com Oliveira (2007, p. 23), [...] "os personagens das histórias em quadrinhos 
materializam representações" [...]. Essas representações são signos e significados que remetem à reflexão sobre o mundo, aqui entendido como relações realizadas no contexto das vivências e percepções do mundo. Essas representações reiteram que a percepção ocorre por meio dos sentidos, e que a cultura influencia a forma de perceber, construir uma visão de mundo e de ter atitudes em relação ao ambiente (TUAN, 1980). Assim, a figura da mulher nas histórias em quadrinhos pode ser vista como uma construção sociocultural, permeada em relações histórico-culturais.

É sabido que o universo dos quadrinhos é impreterivelmente masculino, ainda mais quando falamos de super-heróis. A figura feminina surgiu timidamente nos comics norte-americanos, entendendo aqui que este tem o mais expressivo mercado de criação, produção e consumo.

A imagem idealizada da mulher, ou melhor, do seu corpo, normatizadas nas HQs são na verdade representações de desejos e fetiches do imaginário masculino. Nos quais os escritores, desenhistas, roteiristas, na grande maioria do sexo masculino, procuram vender um modelo de mulher, ou pelo menos o que acreditam ser um.

A partir desta modelagem da mulher nos quadrinhos, é percebida pelo seu corpo, sua sensualidade e suas formas externas, passando, assim, a fazer parte do desejo e sendo representada por 'atributos de seu corpo', não sendo dessa maneira evidenciada as reais capacidades e qualidades da mulher heroína, diferente dos personagens do sexo masculino que, geralmente, são representados e percebidos por sua força, inteligência e poder.

Nesse contexto, Pecora (1999), a rigidez de fórmulas permite que o universo dos super-heróis continue sendo predominantemente habitado por homens brancos, com mulheres como coadjuvantes - saudáveis e atraentes ou velhas e frágeis, mas raramente como iguais.

Os quadrinhos desde seu surgimento, sempre estiveram adaptados e integrados ao contexto histórico-cultural no qual estavam inseridos. A linguagem do corpo feminino expressa nos enredos das HQs, expressões de aspirações, valores e pré-conceitos de seus criadores.

Segundo Siqueira e Vieira (2008, p. 183), "corpo é, desde o nascimento, o principal instrumento de interação entre o homem e o mundo". É dessa forma a justificativa da valorização dos atributos do corpo feminino nas histórias em quadrinhos, é a partir da visualização do corpo das personagens que muitos adolescentes terão interação com o mundo do prazer.

Segundo Merleau-Ponty (1971), é pelo corpo que temos a consciência do mundo, e é do mundo que tiramos nossa percepção do corpo, ou seja, ao mesmo tempo em que construímos a consciência do que é mundo pelo corpo, é do mundo, do que é posto é que percebemos o corpo. Isso porque segundo Nicholson (2000, p. 9), "a sociedade forma não só a personalidade e o comportamento, mas, também, a maneira como o corpo aparece", ou seja, "o próprio corpo é visto através de uma interpretação social”.

As histórias em quadrinhos se apresentam num espaço da comunicação não-verbal, em que o corpo adquire um papel importante se comunicando por si só. Assim, as HQs como qualquer outro meio de comunicação, transmitem valores que variam de sociedade e tempo (SIQUEIRA \& VIEIRA, 2008).

O corpo, principalmente o feminino, passa por uma construção na cultura de massa, ele adquire novos sentidos, que vêm da "necessidade" do corpo sarado e esbelto. O corpo feminino, segundo Bourdieu (2007), se apresenta como um objeto de trocas simbólicas, em que o sentido vem de fora, isto é, da sociedade (masculina). O corpo é 
dotado de sentidos diversos e valores simbólicos, é instrumento de relação do homem com o mundo, sobre o qual se inscrevem elementos da cultura. É dentro dessa perspectiva, que as HQs podem possibilitar compreender a construção do discurso sobre o corpo e as forças atuantes sobre ele (SIQUEIRA e VIEIRA, 2008).

A simples observação da figura feminina já mostra que a mulher não foi destinada a grandes trabalhos intelectuais ou tampouco físicos. Ela carrega a culpa da vida não por meio da ação, mas do sofrimento, por meio das dores do parto, do cuidado com as crianças, da submissão ao homem, para quem ela deve ser uma companheira paciente e alegre (SCHOPENHAUER, 2004).

O sexo masculino é o que dita a aparência da mulher, dentro das regras do que ele acredita ser a imagem da mulher ideal, mulher que comporta tanto o corpo da sexualidade e/ou da maternidade. Nas palavras de Oliveira (2002, p.43):

O corpo feminino é o locus onde se concentra o maior número de atributos sexuais e a ele ainda podem ser agregados outros elementos - cabelos e roupas - que são transformados tantas vezes quanto o padrão de beleza venha determinar. Assim, nas histórias em quadrinhos, o corpo feminino é construído (...), não como corposujeito, mas como corpo-território para posse e deleite do outro, ou corpo-padrão, no qual as múltiplas identidades da mulher são unificadas e fixadas em representações que significam e resignificam uma instância de vigilância e controle sobre sua sexualidade.

A figura da mulher surgiu de forma timidamente nas HQs, o papel da mulher era de coadjuvante ao lado do homem, ou de objeto de diversão, um exemplo é as tiras inglesas de Norman Pett de 1932. É uma das primeiras tiras inglesas a tratar a nudez, esta sendo feminina. Os quadrinhos são da personagem Jane роиса Roupa, que sempre se atrapalha.

Surgem as super-heroínas dentro desse universo, sendo a primeira super-heroína mais conhecida a Mulher Maravilha (Wonder Woman), a personagem surge em um importante momento da história americana, durante a Segunda Guerra Mundial, na qual falaremos mais adiante. Os homens estavam na guerra e as mulheres passaram a cumprir os papéis que eram delimitados aos homens. A figura da mulher se resignifica com o término da Segunda Guerra, surge com marcas de gênero associadas à sexualização, debilidade física, futilidade, entre outras.

A figura do sexo não é representada como mulher, não é vista com o seu valor, mesmo nos quadrinhos é evidente que está em segundo plano. Mesmo com a evolução da sociedade, ainda não passa de uma figura que é demonstrada de forma errônea, causando assim sua errada interpretação, nesse sentido é importante observar Santos (2008), que deixa clara a importância da interpretação correta, visto que a partir daí o sentido das coisas terá seu certo valor.

O sentido que tem as coisas, isto é, seu verdadeiro valor, é o fundamento da correta interpretação de tudo que existe. Sem isso, corremos o risco de não ultrapassar uma interpretação coisicista de algo que é muito mais que uma simples coisa, como os objetos da história. Estes estão sempre mudando de significado, com o movimento das sociedades e por intermédio das ações humanas sempre renovadas (SANTOS, 2008, p. 32). 
A partir de tais percepções, fica evidente a importância da compreensão do recorte de gênero, pois com a construção de tal conhecimento passamos a entender como essas desigualdades entre homens e mulheres no mundo "real" acabam sendo representadas nos quadrinhos."O conceito de gênero permite compreender que não são as diferenças dos corpos de homens e mulheres que os posicionam em diferentes hierarquias, mas sim a simbolização que a sociedade faz delas" (SILVA, 2009, p. 36).

Tratam da construção social dos papéis desempenhados por homens e mulheres na sociedade. Tem caráter relacional, ou seja, o entendimento de um implica consequentemente, no entendimento do outro. Em outros termos, pode ser interpretado como um conjunto de normas modeladoras dos seres humanos aplicadas a homens e mulheres, sendo expressas nas relações sociais públicas e privadas dessas categorias (SAFFIOTI, 1999).

As relações de gênero, no dia a dia do homem e da mulher, são representadas e observadas nas revistas em quadrinhos, nas quais a mulher vem aparecendo como heroínas. Tal heroísmo, dependente e submisso aos heróis masculinos que são mostrados como fortes e viris. O termo gênero representa uma construção cultural central nos estudos e no movimento feminista, mesmo que nas últimas três décadas tenha se tornado ubíquo e ambíguo (STOLKE, 2004).

Duas figuras femininas de super-heroínas aparecem nas HQs, uma tendo super-poder e a outra não, mas que igualmente combatem o crime e traz a paz aos cidadãos norteamericanos, é a Batmoça e a Super-Moça. Ambas são parceiras de grandes nomes dentro dos comics de super-heróis, o Batman e Super-Homem.

As duas super-heroínas apesar de terem super-poder, no caso da Super-Moça e lutarem contra o crime, são sempre salvas por seus parceiros nas narrativas. E outro vilão, talvez até mais perigoso do que os criminosos com quem lutam, é sua 'feminilidade'.

Ficando, assim, evidente sua incapacidade para solução de problemas, mesmo que Super-Heroínas. Deixa, dessta forma, claro que mesmo nos quadrinhos o machismo impera, representando assim evidente a falta de capacidades ou mesmo possibilidades femininas, assim explica Mill (2006, p. 66):

a opressão e subordinação das
mulheres seriam solucionadas
através de uma reforma das
instituições, impulsionada pelo
princípio da "perfeita igualdade". A
eliminação dos resquícios
tradicionais que sustentam a
dominação feminina presentes na
legislação moderna seria garantida
graças à tendência inevitável de
'aperfeiçoamento
humanidade'.

Em alguns enredos elas foram traídas por serem mulheres, um dos casos é quando a Batmoça, durante uma de suas lutas, deixa seus parceiros em situação difícil com os inimigos, porque parou para arrumar sua máscara e tirar lama de seu rosto, o que ajuda na fuga dos criminosos. O narrador frisa "e como qualquer outra moça..." (Os Rasgões do uniforme da Mulher Morcego, 1969, p. 7).

A partir desse esboço, entendemos o que é ser mulher no imaginário masculino, que a feminilidade esta associada à futilidade e vaidade, que a mulher, por mais que tenha 'poderes' e possua um cargo de grande responsabilidade, ela vai ser sempre traída por ser mulher, por acreditarem que sua aparência venha em primeiro lugar. $\mathrm{O}$ narrador ajuda a entender esse imaginário, quando solta 'e como qualquer outra moça', 
ou seja, ela é como qualquer outra moça que não tenha essa responsabilidade de lutar contra o crime, quando o discurso da aparência emerge. No entanto, a Batmoça é uma mulher como outra qualquer, não pelo fato de ser vista como fútil, mas por fazer parte dessa categoria de gênero feminino, só que com um agravante a mais ela luta contra o crime com suas próprias mãos.

Deve entender que a feminilidade não é uma força natural que precisa apenas ser controlada e disciplinada, existem mulheres que não fazem parte do discurso dito feminino, que a mulher deve se casar e ter filhos, que ela deve escolher profissões mais suaves e menos perigosas, assim como existem mulheres que escolhem ser tudo isso. A feminilidade existe ou não em um corpo feminino, nem toda mulher vai ser vaidosa.

Nesse sentido, é importante observar Silva (2009), pois hoje a mulher deve ser observada a partir de outro prisma. Existe a real necessidade da desconstrução desse perfil vulgar e fútil dessa mulher descrita nas historias em quadrinhos.

Trata-se das relações desiguais de poder impostas culturalmente entre homens e mulheres, relações estas que vêm a influenciar nos modos de organização e representações sociais. Cabe também definir sexo, que se refere ao conjunto das características que distinguem os seres vivos, com relação a sua função reprodutora, está relacionado a condições ou diferenças biológicas relacionadas aos corpos humanos, e não a cultura como no caso de gênero. (SILVA, 2009, p. 58).

Nesse mesmo episódio que a Batmoça fora traída por sua feminilidade, ela é ajudada pela mesma. É quando ela rasga seu uniforme, deixando à vista suas pernas e distraindo, assim, os criminosos, fazendo com que Batman e Robin os capture. Dessa forma, a mulher é vista, mais uma vez, como superficial, que o único poder que ela realmente tem é sua beleza e sensualidade, sendo que esta é também prejudicial para ela. É uma contradição que o próprio autor não consegue analisar direito.

Quem nunca leu uma revista da Turma da Mônica, a eterna baixinha, gorducha e dentuça. A Mônica também aparece no discurso normativo masculino do que é feminino e masculino. Ela é um dos casos excepcionais, pois surge primeiramente representada por estereótipos característicos do sexo masculino, ela é agressiva, impõe seu poder aos meninos pela força, e essas características são ditas masculinas. Ela é uma personagem que foge aos padrões femininos.

Com o tempo Mônica se enquadra dentro do discurso do feminino, ela aparece mais meiga, frágil, olhando mais para os meninos, ou seja, características das mulheres, mas nunca perde suas principais características que é ser baixinha, gorducha e dentuça. Essa mudança da personagem é um pedido da turma, das meninas, principalmente, para ela ser mais feminina. Entendemos aqui, que a própria mulher se vê de forma frágil, que não pode ganhar pela força, esse imaginário perpassado entre as mulheres, pois está ligado a aspectos histórico-culturais.

Hoje ainda existem as revistas da Turma da Mônica Jovem, nas quais a Mônica esta totalmente feminizada. Com a ausência das mulheres na indústria dos quadrinhos, estas são apresentadas nas HQs, principalmente norte-americanas, com marcas de sexualização, futilidade, debilidade física e mental, é instável emocionalmente e irracional, esta última quando o sexo masculino está inserido na trama. 
Vilãs, Mocinhas ou Heroínas: linguagem do corpo feminino nos quadrinhos

Heroísmo e Sedução: Uma Análise da Mulher Maravilha

Até a Segunda Guerra Mundial as mulheres apenas escreviam quadrinhos infantis. Com a saída dos homens para guerra, as mulheres começam a assumir postos na sociedade que eram somente masculinos, se fazendo presente também na elaboração dos comics.

Em 1941, Willian M. Marston criou a primeira mulher super-heroína, a MulherMaravilha (Wonder Woman), ela foi à única super-heroína adulta e com revista própria durante alguns anos. Ela tem sua gênese durante a Segunda Guerra Mundial, onde surgem outros super-heróis como SuperHomem. O surgimento da personagem vem como ícone da representação feminina, até então inexistente (NOGUEIRA, 2010).

A história da Mulher Maravilha é assim: tudo teria começado em 1200 a.C. , quando cinco deusas do olimpo criaram as amazonas, uma raça de mulheres guerreiras e imortais, para difundir a sabedoria dos deuses entre os homens. As amazonas falharam e como castigo foram isoladas na Ilha de Themyscira, localizada sobre o mundo tártaro. A nova função das amazonas passou a ser evitar que as terríveis criaturas do Tártaro se espalhassem pelo mundo. Os séculos se passaram até que os deuses presentearam Hipólita, a rainha das amazonas, com uma filha. A menina recebeu vários dons olímpicos e foi batizada de Daiana em homenagem a Daiana Trevor, uma pilota da Força Aérea Americana, que caiu em Themyscira durante a Segunda Guerra Mundial. Quando a princesa chegou à idade adulta, o Olimpo exigiu que se organizasse um torneio para selecionar uma campeã entre as amazonas. A guerreira vencedora seria destacada para combater o deus da Guerra, que se espalhara sobre o nosso planeta. Daiana participou secretamente, para que sua mãe não soubesse e venceu o torneio. Como campeã, recebeu um uniforme inspirado na bandeira americana, encontrada no avião de Daiana Trevor. Ela ganhou também um laço mágico, capaz de extrair a verdade de qualquer pessoa, e um par de braceletes que a protegia das balas, raios e outras coisas (NEIS, 2010, p. 5-6).

A personagem da Mulher-Maravilha (figura 1) surgiu em um momento históricocultural perturbador, em meio a Segunda Guerra, com uma sociedade cheia de tabus, na qual homens e mulheres tinham seus papéis definidos e inquestionáveis.

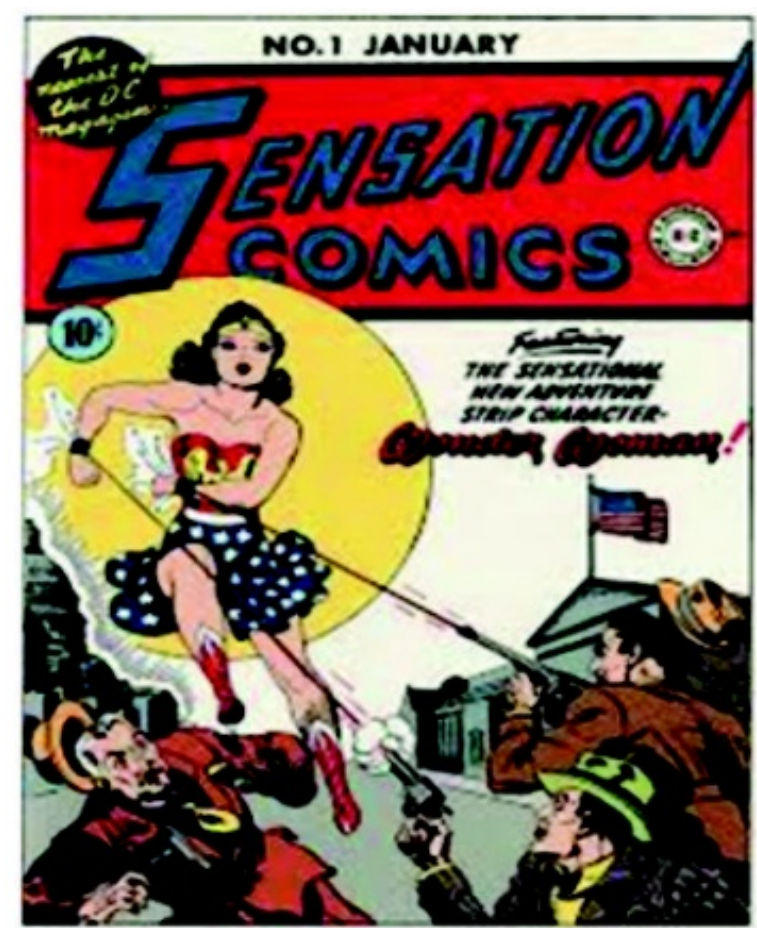

Figura 1: Mulher Maravilha lutando contra inimigos ${ }^{1}$.

Kelli Carvalho Melo e Maria Ivanilse Calderón Ribeiro 
Marston, o criador da Mulher-Maravilha, acreditava que as mulheres eram por natureza mais gentis, honestas, confiáveis que os homens, talvez seja por essa razão que criou uma personagem mulher num momento histórico nada comum, para passar certa segurança às mulheres que ficavam em seu lares a espera de seus maridos e filhos.

Dessa forma, ele busca, através de sua personagem, criar entre as mulheres da época tratamento estético e textual, que elas pudessem se ver na super-heróina e buscar forças para superar tal momento, visando reconstituir na personagem o seu próprio campo de representações, de como as mulheres deveriam se ver nesse momento, era a força da mulher norte-americana representada na personagem.

As mulheres foram instigadas a assumirem os trabalhos nas fábricas e indústrias bélicas para defender o estilo de vida americano, e evitar uma recessão econômica. A personagem da Mulher-Maravilha se caracteriza como uma mulher até então desconhecida na sociedade patriarcal estadunidense, ao invés de frágeis e indefesas, heroínas capazes de superar qualquer adversidade com força, inteligência e beleza (CAIXETA, 2012).

Dessa forma, a função em meio à guerra da heroína Mulher-Maravilha foi de contrastar com o dos super-heróis clássicos, apesar de seus enormes poderes, ela somente os usava-os quando necessário, segundo Santos (2008, p. 11):

Ela resolvia tudo com a inteligência, astúcia e a utilização de seu laço mágico, no qual quem fosse amarrado só conseguia falar a verdade. Ao contrário dos outros super-heróis, a sua missão não era só acabar com o crime, mas também reformar os criminosos e torná-los cidadãos de bem.
Compreendemos que o papel assumido pelas mulheres, durante esse período conturbado, era bem mais que cuidar do lar, filhos, trabalhar nas fábricas e manter os soldados abastecidos, mas manter uma América estadunidense para o regresso de seus soldados e o American way of life.

Inicialmente, a super-heroína rompeu barreiras impostas pelo preconceito machista da época, uma mulher que luta igualmente como um homem, que se torna importante na luta contra os inimigos norte-americanos, assim como os demais super-heróis, ela carrega as cores da bandeira dos Estados Unidos no peito.

A vestimenta é simbólica. Ela consegue transmitir instantaneamente a força, o caráter, a ocupação e a intenção de quem a usa. A maneira como a personagem a usa também pode transmitir uma informação ao leitor. Nos quadrinhos, assim como acontece nos filmes, objetos simbólicos não narram apenas, mas ampliam a reação emocional do leitor (EISNER, 2008, p. 26).

A personagem da Mulher-Maravilha foi pensada o mais próximo da vida da mulher norte-americana. Um exemplo é uma das edições, ainda na década de 1940, que a heroína fica amiga de uma adolescente chamada Etta Candy, esta era líder de um grupo de alunas do ensino médio, que serão, por um breve momento, companheiras da heroína contra o mal. Etta era uma adolescente fora dos padrões de beleza e acima do peso, Marston, queria passar as [...] "mulheres que aquela força e independência da amazona estariam ao alcance de todas as mulheres, sem restrições a padrões estéticos de qualquer natureza" (CHACON, 2010, p. $55)$. 
A personagem Diana (Mulher-Maravilha) foi também pensada para diversificar o público leitor, e atender as leitoras do sexo feminino, essa diversidade vem justamente do momento de mudanças dos quadros sociais do país (VERGUEIRO, 2004). Ela é criada com a eclosão do trabalho feminino no período da Segunda Guerra, a personagem é uma contrapartida ao super-herói SuperHomem (WESCHENFELDER, 2012 apud BOFF, 2014).

No entanto, com o passar dos anos, já com o fim da Segunda Guerra, muda-se a maneira de representar a Mulher-Maravilha, ela aparece mais sexualizada, mostrando suas curvas, sua feminilidade, precisa ser salva diversas vezes pelos verdadeiros heróis, os homens. Em um dos episódios da Liga da Justiça, ela é obrigada a fazer café e servir para os seus parceiros, nunca imaginaríamos ver tal cena, uma Amazona guerreira servindo café. Ressignifica a maneira como a Mulher-Maravilha é representada nas HQs, muda-se o padrão, sendo mais explorando os dotes físicos da personagem.

Quando se reduz o valor de uma pessoa a apenas um de seus aspectos e potenciais, no caso aqui os atributos sexuais da personagem mulher, é desumanizá-la, o que deixa de qualificar como um indivíduo completo.

Portanto, contribuindo para normatizar uma cultura de desigualdade que se reflete tanto nos quadrinhos quanto na vida real e quotidiana.
Ao ser observada a figura 2, pode ser inferir que é a imaginação e/ ou a necessidade masculina com relação à mulher, a mulher objeto para realização de desejos, transforma e traz esta com diferentes características, mas sempre relacionadas ao corpo, nesse contexto deve-se observar as relações entre homem e mulher em busca da desconstrução da mulher como figura para satisfação de desejo.

Figura 2: Resignificação da maneira de representar o corpo e 'atitudes' da Mulher-Maravilha².

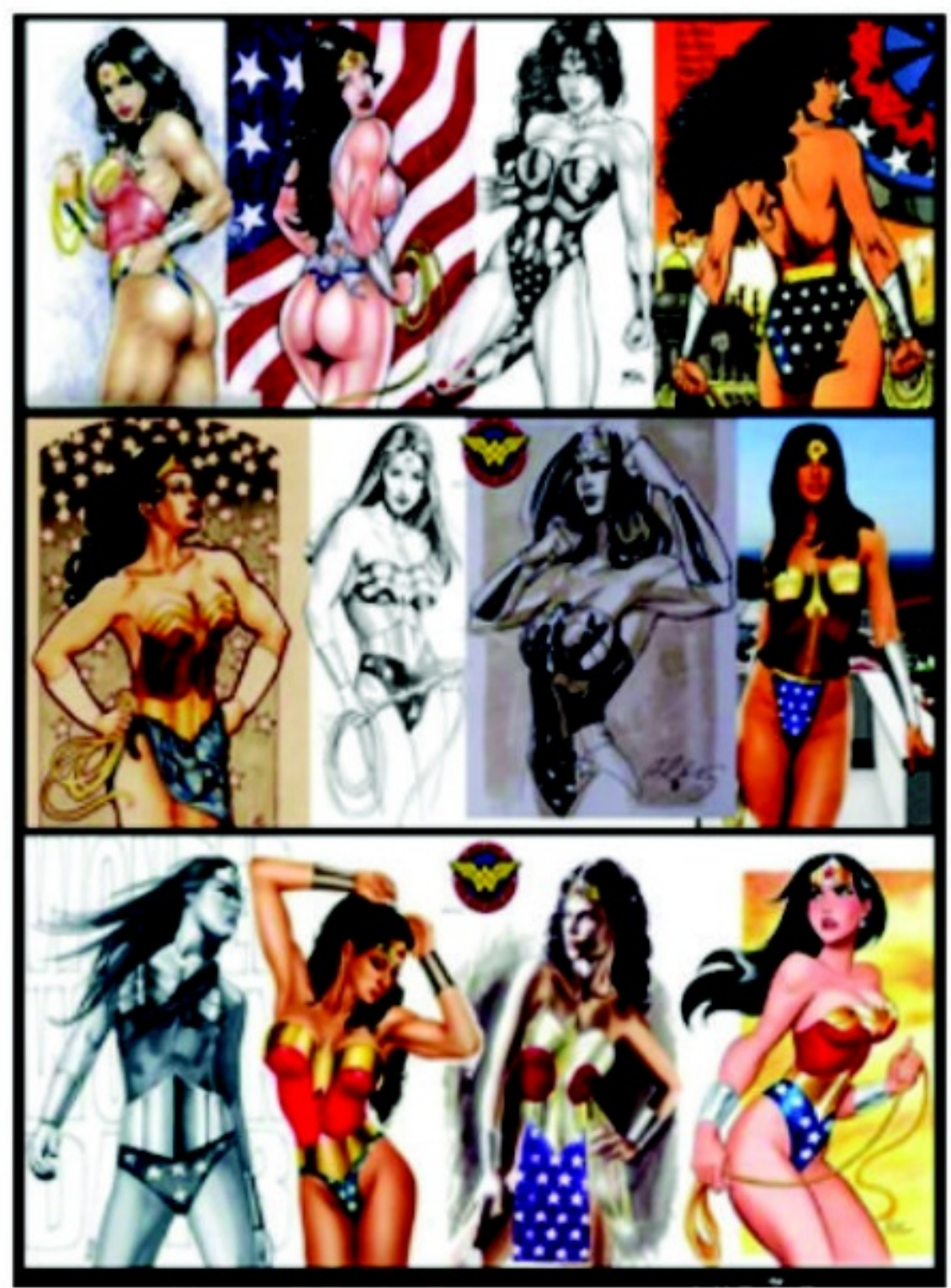


O termo gênero não explicita necessariamente que as desigualdades são inerentes entre os homens e mulheres, que a hierarquia entre estes é presumida. Pode ser entendido como um conjunto de normas de modelagem homens e mulheres, fazendo parte do mecanismo de ordem social, que cada mulher interpretará de forma singular (SAFFIOTI, 1995, p. 34).
É evidente que os quadrinhos ainda possuem o foco de dialogar com o publico e imaginário masculino. As personagens femininas e seus corpos, o que o sexo masculino e até mesmo o feminino acreditam ser feminilidade devem ser desconstruídos das histórias em quadrinhos, pois uma personagem que consegue lutar com diversos vilões com as roupas justas e decotadas e salto alto vai além de ser heroína (figura 3).

Figura 3: Sátira aos heróis ${ }^{3}$.

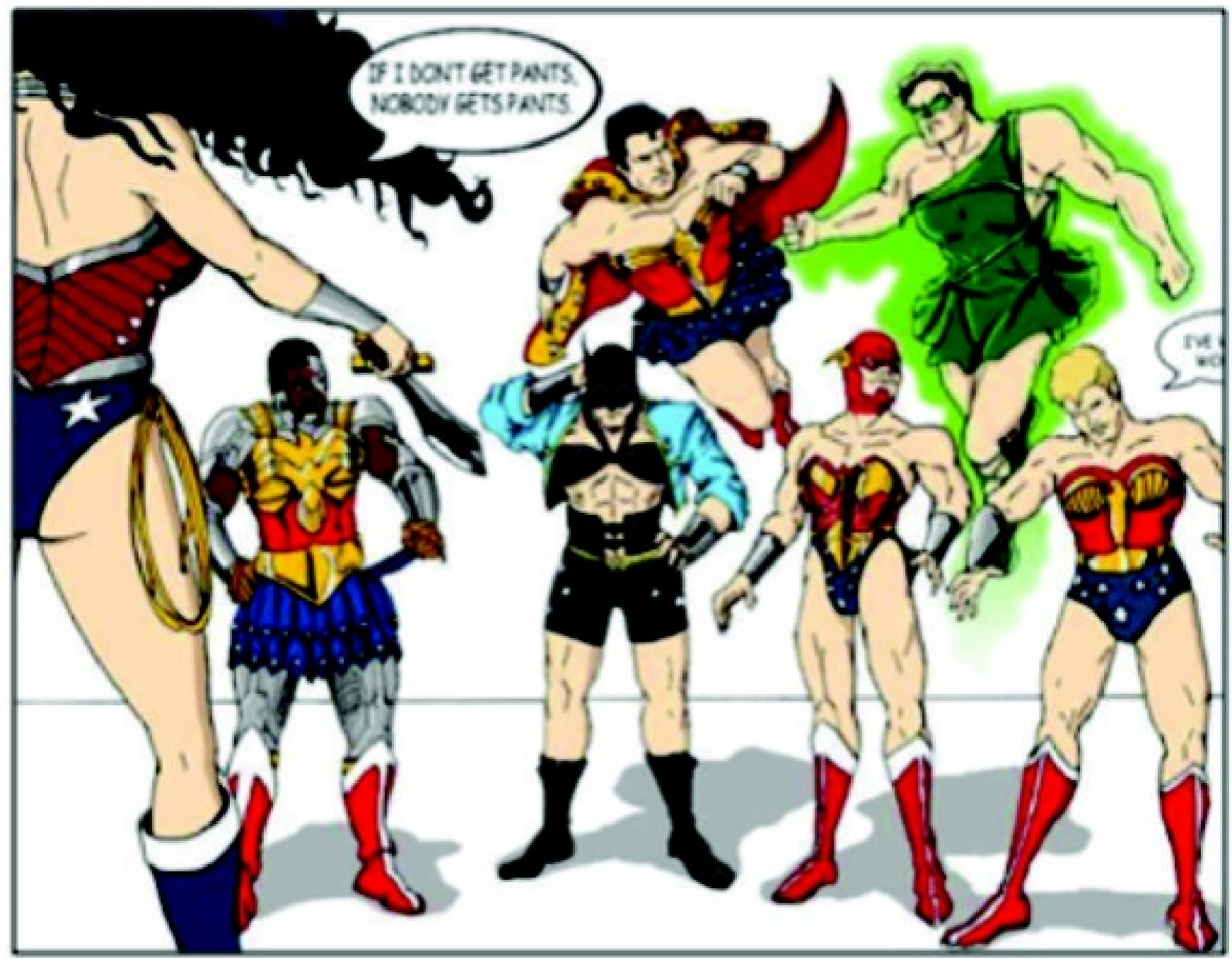




\section{Considerações Finais}

A pesquisa permite perceber que o papel da mulher. muitas vezes, restringe-se a papéis com pouco valor, ou até mesmo insignificantes ou, de alguma forma, demonstrando o lado dependente e submissão ao sexo masculino, ou seja, os heróis da história. Em poucas histórias a mulher assume o papel de heroína por sua força, sagacidade, inteligência deixando de ser a mocinha indefesa esperando seu herói vir buscá-la e protegê-la. Demonstrando, assim, de certa forma, uma incapacidade ou submissão a qual a mulher é vista ou inserida por gerações.

A partir dessa análise de referenciais, fica evidente o papel que a mulher assume, ou melhor, que é imposto a ela nas histórias em quadrinhos, entendendo que são reflexos da sociedade. Esses papéis, delimitados a partir do sexo, devem ser desconstruídos, e é nessa análise que aspiramos uma mudança de paradigmas dentro da sociedade e consequentemente nas HQs.

E também demonstra o estudo de gênero, no qual enfatiza o surgimento de um novo pensar em uma nova sociedade, e este tipo de estudo não pode ser realizado isoladamente, onde ao observar as relações de gênero não se pode deixar de observar demais elementos e características da sociedade, pode-se perceber que observar as relações de gênero vai muito além da observação apenas com relação ao sexo dos componentes da relação.

Portanto, é muito importante que questionamentos a respeito dos modos de representar homens e mulheres nos quadrinhos sejam levantados diariamente. Pois esses dois sexos são, infelizmente, apreendidos e representados de formas distintas, não só nos quadrinhos mas em qualquer meio de comunicação. Lembrando que o modo de representar uma pessoa é reflexo da visão da sociedade e como ela será tratada. A partir desse entendimento pode-se surgir alternativas para desconstruir essa imagem.

$1 \quad$ Fonte: https://www.google.com.br/search?

2 Fonte: https://www.google.com.br/search

3 Fonte: http://ladyscomics.com.br/debatemulheres-nos-quadrinhos-gibicon-01

\section{Referencias}

ARANHA, Maria Lucia de Arruda; MARTINS, Maria Helena Pires. Filosofando - Introdução a Filosofia. São Paulo: Moderna, 1986.

BARCELLOS, Janice Primo. O feminino nas histórias em quadrinhos. Disponível em

$<$ http://www.eca.usp.br/nucleos/nphqeca/aga que/ano2/numero4/artigosn4_1v2.htm>.

Acesso em: 20/02/2015.

Batman. Os Ragões do uniforme da Mulher Morcego. Rio de Janeiro, EBAL, n. 92, Fevereiro/1969, p. 19.

BOFF, Ediliane de Oliveira. De Maria a Madalena: representações femininas nas histórias em quadrinhos. 2014. Tese (Doutorado em Comunicações e Artes) Universidade de São Paulo, São Paulo.

BOURDIEU, Pierre. A dominação masculina. $5^{\text {a }}$. ed. Rio de Janeiro: Bertrand Brasil, 2007.

CARVALHO, Kelli Carvalho. Uma Linguagem Alternativa no Ensino Escolar: as histórias em quadrinhos na mediação do ensino e aprendizagem da geografia. Ateliê 
Geográfico, v. 7, n. 1, p. 260 - 283, 2013.

CAIXETA, Sharmaine Pereira. Anos dourados: a mulher-maravilha e o papel da mulher norte-americana durante a $2^{\mathrm{a}}$ Guerra Mundial. Revista Temática, v. 8, n.4, p. 1 $12,2012$.

CHACON, Beatriz da Costa Pan. A Mulher e a Mulher-Maravilha: Uma questão de história, discurso e poder (1941 a 2002). 2010. Dissertação (Mestrado em História Social) - Universidade de São Paulo, São Paulo.

EISNER, Will. Narrativas gráficas: princípios e práticas da lenda dos quadrinhos. São Paulo: Devir, 2008.

MERLEAU-PONTY, Maurice. Fenomenologia da percepção. Rio de Janeiro: Freitas Bastos, 1971.

MINAYO, Maria Cecília de Souza. O Desafio do Conhecimento. São Paulo: Hucitec/Abrasco, 1992.

NEIS, Josemara. Mulher Maravilha. Disponível em: $<$ http://www.fazendogenero.ufsc.br/7/artigos/ J/Josemara_Neis_08.pdf $>$. Acesso em : 20/02/2015.

NICHOLSON, Linda. Interpretando o Gênero. Revista Estudos Feministas, v. 8, n. 2, p. 9 - 41, 2000.

NOGUEIRA, Natania Silva. Representações femininas nas histórias em quadrinhos da EBAL. História, Imagem e Narrativa, n. 10, p. 1 - 14, 2010.

OLIVEIRA, Selma Regina Nunes. Mulher ao Quadrado - as representações femininas nos quadrinhos norte-americanos: permanências e ressonâncias (18951990).Brasília: Editora Universidade de Brasília: Finatec, 2007.

OLIVEIRA, Selma Regina Nunes. O jogo das curvas. Revista Comunicação e Espaço Público, v. 5, n. 1/ 2, p. 32 - 43, 2002.

TUAN, Yi-Fu. Topofilia. Um estudo da percepção, atitudes e valores do meio ambiente. São Paulo: DIFEL, 1980.

PÉCORA, Alcir. Teatro do sacramento. São Paulo: Editora da Unicamp/Edusp, 1999.

PESAVENTO, Sandra Jatahy. História e História Cultural. Belo Horizonte: Autêntica, 2003.

SANTOS, Milton. Por uma outra globalização: do pensamento único à consciência universal. $17^{\mathrm{a}}$ ed. Rio de Janeiro: Record, 2008.

SANTOS, Aline Martins dos. A Segunda Guerra Mundial nas histórias em quadrinhos. Rio de Janeiro/RJ: XIII Encontro de História Anpuh, 2008.

SAFFIOTI, Heleieth Iara Bongiovani; Almeida, Suely Souza de. Violência de gênero: poder e importância. Rio de Janeiro: Revinter, 1995.

SAFFIOTI, Heleieth Iara Bongiovani. Já se mete a colher em briga de marido e mulher. São Paulo em Perspectiva, v. 13, n. 4, p. 82 - 91, 1999.

SHOPENHAUER, Arthur. A arte de lidar com as mulheres. São Paulo: Martins Fontes, 2004.

STOLKE, Verena. La mujeres puro cuento: la cultura del género. Estudos Feministas, v. 
Vilãs, Mocinhas ou Heroínas: linguagem do corpo

feminino nos quadrinhos

12, n. 2, p. 77 - 105, 2004.

SILVA, Susana Veleda da. Os Estudos de Gênero no Brasil: Algumas Considerações. Revista Bibliográfica de Geografía y Ciencias Sociales, v. 5, n. 262, s/p, 2000.

SILVA, Joseli Maria. Geografias Subversivas: discurso sobre espaço, gênero e sexualidades. Ponta Grossa: Toda palavra, 2009.

SIQUEIRA, Denise; VIEIRA, Marcos. De comportadas a sedutoras: representações da mulher nos quadrinhos. Revista Comunicação, mídia e consumo, v. 5, n. 13, p. 179 - 197, 2008.

VERGUEIRO, Waldomiro. As histórias em quadrinhos e seus gêneros $\mathrm{V}$ : os quadrinhos protagonizados por mulheres. Disponível em $<$ http://www.ofaj.com.br/colunas_conteudo.p hp? cod=146>. Acesso em: 20/02/2015.

Recebido em 25 de maio de 2014. Aceito em 02 de dezembro de 2014. 